\title{
Regulación jurídica del agua embotellada y del arsénico en la provincia de Buenos Aires, Argentina
}

\section{POR VERÓNICA LUCÍA CÁCERES $(*)$ Y CLARA MARÍA MINAVERRY $\left({ }^{* *}\right)$}

\begin{abstract}
Sumario: I. Introducción.- II. El mercado de aguas embotelladas en Argentina.- III. La regulación del arsénico en el agua en Argentina.IV. El particular caso del noreste de la provincia de Buenos Aires y la percepción de la población.- V. Conclusiones.- VI. Bibliografía.
\end{abstract}

Resumen: el presente trabajo, en primer lugar, presentará una caracterización del mercado de agua embotellada en Argentina y de su institucionalidad. En segundo lugar, se expondrá un debate actualizado sobre los niveles de arsénico, la situación de las empresas vinculadas con el comercio de agua embotellada, la normativa vigente, la percepción de la población respecto al agua que se distribuye en las redes y el agua embotellada. Por último, se presentarán una serie de conclusiones. Es posible concluir que las empresas que comercializan agua embotellada no están obligadas a informar el componente de arsénico y que esto podría interferir con los derechos constitucionales de los consumidores. Además, la regulación jurídica de la calidad del agua presenta lineamientos contradictorios e insuficientes y la población del noreste de la provincia de Buenos Aires en su mayoría afirma que el agua embotellada presenta una calidad superior que la de red condicionando su consumo.

$(*)$ Doctora en Ciencias Sociales. Investigadora asistente, Consejo Nacional de Investigaciones Científicas y Técnicas (CONICET), sede de trabajo: Instituto de Investigaciones Jurídicas y Sociales Ambrosio Lucas Gioja, Facultad de Derecho, Universidad de Buenos Aires. Investigadora y Prof. Adjunta, Universidad Nacional de General Sarmiento y Universidad Nacional de Luján.

(**) Doctora en Derecho. Investigadora adjunta, Consejo Nacional de Investigaciones Científicas y Técnicas (CONICET), sede de trabajo: Instituto de Ecología y Desarrollo Sustentable (INEDES). Prof. Adjunta Ordinaria de Derecho Ambiental, Universidad Nacional de Luján y Prof. de Posgrado, Universidad Tecnológica Nacional. 
Palabras clave: agua embotellada - derecho - calidad - comunidad

\section{Bottled water and arsenic regulation in the province of Buenos Aires, Argentina}

Abstract: in the first place, this paper will present a characterization of bottled water market in Argentina and its institutionalism. In the second place, we will expose an updated debate about arsenic levels, the situation about companies related to the bottled water business, the present legislation, the perception of the population about water which is distributed in networks and of the bottled one, and at last, we will present some conclusions. Its is possible to conclude that companies which commercialize bottled water are not obliged to inform about arsenic and this could interfere with constitutional consumer's rights. Also, the legal regulation about water quality presents contradictory and insufficient guidelines and the majority of the population of the Northeast of the Province of Buenos Aires states that bottled water have higher quality than the one which is provided by the network and this conditions their consumption.

Keywords: bottled water - law - quality - community

\section{Introducción}

El agua embotellada forma parte de la industria alimenticia, específicamente del mercado de bebidas sin alcohol que se encuentra en pleno crecimiento a nivel mundial. Se trata de un mercado altamente concentrado en dos grupos franceses: Aguas Danone y Nestlé Waters. En la República Argentina las marcas líderes se encuentran asociadas a estos grupos y se adicionan las marcas de Coca Cola y Pepsico y segundas marcas en expansión.

La República Argentina es un país federal en el que le "corresponde a las provincias el dominio originario de los recursos naturales existentes en su territorio" (artículo 124 de la Constitución Nacional - $\mathrm{CN}-$ ) y al Estado nacional la responsabilidad de dictar "las normas que contengan los presupuestos mínimos de protección ambiental y a las provincias, las necesarias para complementarlas, sin que aquéllas alteren las jurisdicciones locales" (artículo $41 \mathrm{CN}$ ). A su vez los parámetros del agua embotellada se regulan mediante el Código Alimentario Nacional que incluye regulaciones sobre las características de los alimentos y bebidas, así como de los establecimientos productores, elaboradores y comercializadores de dichos productos, envases, aparatos y accesorios para alimentos y técnicas analíticas afines. Por lo que la temática del agua embotellada cruza un conjunto de disposiciones que involucran distintos niveles de gobierno. 
El presente trabajo centra la mirada en la regulación que alcanza al mercado de aguas embotelladas en la República Argentina. El agua embotellada asume un lugar crítico en las áreas donde el servicio de agua no se encuentra disponible o tiene serias dificultades en materia de calidad. El arsénico conforma uno de los desafíos más importantes, en términos de calidad, que enfrenta la gestión del agua en el país. Se trata de un elemento natural distribuido en la corteza terrestre que se encuentra en cantidades pequeñas en rocas, suelos, agua y aire y se caracteriza por no ser perceptible por el olor, color, aunque es muy tóxico en su forma inorgánica. La toxicidad del arsénico puede ocurrir de forma aguda tras la ingesta de cantidades importantes en un periodo breve, o de forma crónica dado el consumo de pequeñas cantidades en un período mayor (Garzonio y Núñez, 2012).

Las empresas que embotellan aguas siguen los lineamientos en materia de calidad, rotulado, envases - entre otros- del Código Alimentario, que las obliga a informar a los consumidores respecto a un conjunto de componentes y otra información relativa al proceso de producción involucrado. Sin embargo, no las obliga a informar respecto de la concentración de arsénico. Los controles sobre los componentes del agua y otras bebidas y alimentos involucran a la Administración Nacional de Medicamentos, Alimentos y Tecnología Médica (ANMAT), dependiente del Ministerio de Salud de la Nación y a otras agencias del Estado nacional, así como de los niveles subnacionales.

El trabajo se realizó, en primer lugar, a partir de la observación documental comparativa y descriptiva de normas jurídicas e informes técnicos estadísticos: en especial se recopiló y analizó las distintas modificaciones que atravesó el Código Alimentario argentino en lo que concierne a la calidad del agua; las actas de la Comisión Nacional de Alimentos y los informes de la Dirección Nacional de Alimentos y Bebidas. En segundo lugar, se recurrió al trabajo de campo realizado desde marzo de 2018 hasta marzo de 2020 en los siguientes partidos del noreste de la provincia de Buenos Aires: San Andrés de Giles: Lobos, Luján, Mercedes y General Rodríguez, donde se realizó una encuesta sobre las condiciones de acceso al agua y la problemática del arsénico. Se realizaron 175 encuestas a personas que habitan o trabajan en el casco urbano de los municipios. Por último, se recurrió al relevamiento exploratorio del mercado de agua embotellada a partir de la selección de una muestra de diez empresas que comercializan agua embotellada en la provincia de Buenos Aires y la caracterización de la información que provee los rotulados.

En primer lugar, presenta una caracterización del mercado de aguas embotelladas en Argentina y la institucionalidad del sector; en segundo, un debate actualizado respecto a los niveles de arsénico, la situación de las empresas vinculadas con el comercio de agua embotellada, la normativa vigente y la percepción de la 
población respecto al agua potable y a la compra de agua envasada, y, por último, se presentarán una serie de conclusiones.

\section{El mercado de aguas embotelladas en Argentina}

El agua es indispensable para la salud, la sostenibilidad de la biodiversidad y del planeta en su conjunto. Su uso es demandado y disputado para el consumo doméstico, industrial, agropecuario, turístico y minero, entre otros. El agua tiene un valor social y cultural vinculado a derechos humanos inalienables y también se transforma en un bien económico para un conjunto de actividades. El acceso al agua potable conforma un derecho humano indispensable para la vida, ya que toda la población tiene que tener su acceso garantizado y su reconocimiento plantea la importancia que la provisión de agua sea: aceptable para el uso personal o doméstico en relación con el color, olor y sabor, garantizar la no discriminación y considerar las necesidades culturales, de género, del ciclo vital y de privacidad; accesible físicamente, dentro o en las cercanías inmediatas de cada hogar, institución educativa o lugar de trabajo; asequible y disponible económicamente, por lo que los costos asociados al acceso no deben comprometer ni impedir el logro y la satisfacción de otras necesidades básicas; suficientes en cantidades y continuo para el abastecimiento de cada persona; y salubre, es decir, libre de microorganismos, sustancias químicas y amenazas radiológicas que pongan en peligro la salud (ONU, 2010, p. 1).

En la economía tradicional los bienes se clasifican de acuerdo con dos principios: la exclusión y la rivalidad. Un bien es excluible cuando es posible impedir que lo utilice otra persona, es decir que se le puede negar su uso. Un bien es rival cuando su consumo por parte de una persona reduce su consumo por parte de otra. Con base en estas características se clasifican a los bienes en: bienes privados, aquellos que son bienes excluibles y rivales; bienes públicos, no son ni excluibles ni rivales y los recursos escasos son rivales, pero no excluibles (Mochón y Becker, 1993). En este sentido, a diferencia del agua de un río, el agua que se envasa o embotella y comercializa se transforma es un bien privado, en tanto es rival y exclusivo y se convierte en una mercancía que se comercializa en mercados específicos dinámicos. En la consolidación del capitalismo como sistema económico dominante se observa la fuerte tendencia a la mercantilización de distintas esferas de la vida, incluida la naturaleza. Polanyi, en 1944, consideró que la naturaleza era una mercancía ficticia, ya que no fue producida para ser vendida. Tal como explica Godelier, el intercambio a través del mercado logró dominar el proceso económico "en la medida en que la tierra y los alimentos (fueron) movilizados por ese intercambio y allí donde la mano de obra se ha convertido en mercancía que puede comprarse libremente en el mercado" (Godelier, 1974, p. 22). 
La mercantilización del agua involucra procesos históricos y asume distintas modalidades y, como explica Castro (2009, p. 11), "hace referencia a la circulación del agua como un bien privado cuyo valor de cambio incluye una ganancia que es apropiada por un agente privado quien detenta el derecho de propiedad". Claramente el agua embotellada es un ejemplo creciente de los procesos de mercantilización, en esta el agua circula como una mercancía "producida" por empresas, mayormente con objetivos mercantiles (Castro, 2009, p. 11).

En la República Argentina los recursos naturales, como el agua, corresponden al dominio de las provincias, aunque la industria del agua embotellada requiera para operar un conjunto de autorizaciones y el cumplimiento de disposiciones establecidas y otorgadas por los Estados provinciales, que incluyen: la autorización de la explotación de una fuente de agua otorgada por el nivel provincial; los patrones de calidad del agua acordados por el nivel nacional mediante el Código Alimentario y las disposiciones de los envases y condiciones de los procesos productivos; y locales, sobre el uso de los servicios públicos. La regulación sobre este sector no incluye regulación económica sobre los precios de los productos, que se determinan de acuerdo con los criterios de las empresas en los distintos mercados. Las empresas, si bien asumen cargas impositivas por su desempeño, solo en algunas provincias se les cobra un canon específico por el uso del agua, que es de dominio de las provincias y es clasificada como un bien público(1).

El agua embotellada forma parte del mercado de bebidas sin alcohol con gran protagonismo desde la década del noventa del siglo XX, cuando creció su consumo en un 50\%. En la República Argentina se encuentra claramente diversificado. Existen más de 200 empresas con marcas y diferentes tipos y sabores, que incluyen desde Pymes que distribuyen aguas en algunas provincias del país, como es el caso de Agua Nuestra en Entre Ríos y Santa Fe, Ivess Hogar, Panizza o Nihuil, cuya distribución recorre la Ciudad Autónoma de Buenos Aires y la provincia de Buenos Aires, hasta empresas ligadas a grandes operadores internacionales del sector como lo es Villa del Sur.

Más allá de la diversificación, el mercado se encuentra liderado por las compañías internacionales, principalmente por Danone que tiene Villavicencio (adquirida en 1999); Villa del Sur y Ser; Nestlé con las marcas Eco de los Andes, Nestlé Pureza Vital y Glaciar. Se trata de un mercado cuya producción y distribución

(1) En el título de bienes, sección $2^{\circ}$ (bienes con relación a las personas), el Código Civil y Comercial de la Nación, que fue reformado en el 2015, establece lo siguiente: "Son bienes pertenecientes al dominio público, excepto lo dispuesto por leyes especiales: (...) c. los ríos, estuarios, arroyos y demás aguas que corren por cauces naturales, los lagos y lagunas navegables, los glaciares y el ambiente periglacial y toda otra agua que tenga o adquiera la aptitud de satisfacer usos de interés general, comprendiéndose las aguas subterráneas" (artículo 235). 
demanda especialización (Correa, 2011) y tiene como componente central la publicidad. Para 2010, el mercado tenía una demanda anual de 650 millones de litros (Burlot, 2010). Aunque la producción de bebidas, aguas, dentro de ellas se destina principalmente al mercado interno, durante 2010-2019 se sostuvo la exportación de agua mineral, el principal país receptor fue Francia; a su vez, se incrementaron la participación de las exportaciones de aguas saborizadas con Chile como principal comprador y la comercialización de hielo con Noruega como principal receptor (Dirección Nacional de Alimentos y Bebidas, Secretaría de Gobierno de Agroindustria, con base en INDEC, 2018).

La Encuesta Nacional de Gastos de los Hogares 2017-2018 del Instituto Nacional de Estadística y Censos señala que el 22,8\% del gasto de consumo de los hogares a nivel nacional se destinaba a la compra de alimentos y a bebidas no alcohólicas (INDEC, 2019).

El mercado de consumo de agua embotellada es dinámico y aunque se encuentre afectado por la recesión económica que enfrenta la República Argentina en los últimos meses, ocupa un espacio importante en el consumo que realizan las personas, en especial las más jóvenes, en tanto las empresas recurren a un conjunto de herramientas publicitarias para consolidar sus productos. La publicidad y el packaging son centrales en la estructura de costos de las empresas. Existen diversos tipos de aguas y hay información que no siempre es clara para los consumidores y que puede generar confusión.

Como sostiene un informe reciente, "diferentes procedencias de las aguas minerales implican diferentes composiciones químicas". Se suele decir que son saludables simplemente porque son naturales, pero este concepto no es coherente, ya que, justamente, las fuentes principales del arsénico (As) en el agua son naturales y provienen de aguas subterráneas, que son las fuentes de aguas minerales o de "fuente" (Red de Soberanía Alimentaria del CONICET, 2018, p. 55). "Aguas que provienen de localizaciones que se pueden considerar prístinas por excelencia, como las aguas endoglaciales, presentan una notable toxicidad, probablemente como resultado del efecto sinérgico de diferentes agentes. Por otra parte, existen aguas mineralizadas artificialmente que también podrían contener niveles elevados de As" (Red de Soberanía Alimentaria del CONICET, 2018, p. 55).

Llamativamente en la actualidad las empresas que se dedican a la producción y comercialización de agua embotellada en el país no tienen la obligación de informar a la población consumidora en sus etiquetas sobre el contenido de arsénico presente en las botellas de agua. El arsénico conforma un claro desafío en la gestión del agua en el país y en otras regiones donde su presencia condiciona los procesos de producción del servicio de agua y otras actividades industriales. 
No solo el consumo de agua embotellada se consolidó en la población más joven, sino que ante la falta de servicio público por red en distintas partes del territorio o frente a problemas graves de calidad del agua que se distribuye en algunas áreas, los hogares recurren a estos productos. Cabe señalar que el país cuenta con un déficit de cobertura de hogares al servicio de agua que, para 2015, solo abastecía al $87 \%$ en las áreas urbanas, donde reside la mayor parte de la población del país (Ministerio del Interior, Obras Públicas y Vivienda, 2017). A su vez presenta áreas comprometidas con la presencia de arsénico de origen natural en una extensa proporción del territorio que incluye la denominada llanura Chaco-pampeana, la región de Cuyo y la región del noroeste del país. La situación más crítica se observa en las provincias de Chaco, Córdoba, Santiago del Estero, Salta, Santa Fe, Tucumán, La Pampa y parte de la provincia de Buenos Aires. Los niveles de arsénico se tornan comparables, de acuerdo con la literatura relevada, con regiones asiáticas como es el caso de Bangladesh (Villaamil Lepori, 2015).

\section{La regulación del arsénico en el agua en Argentina}

\section{III.1. Sobre el arsénico}

La contaminación del agua con niveles elevados de arsénico afecta a varias provincias del territorio argentino. La presencia tiene un origen natural se relaciona con algunos de procesos geológicos que han afectado y afectan esta región, especialmente a las aguas subterráneas (Garzonio y Núñez, 2012).

A la par que se difunde información respecto a la situación, en algunas áreas afectadas la población comienza a reclamar a los estados provinciales, que en la legislación argentina poseen el "dominio de los recursos naturales" y son responsables de la prestación, regulación y control del servicio público de agua por red. Esto sucede en varios municipios de la provincia de Buenos Aires (Cáceres, 2019; Cáceres y Minaverry, 2019), donde se observa cómo distintos actores reclaman por el derecho al agua mediante procesos políticos y judiciales. En estos casos y cuando la población tiene la posibilidad económica adquiere agua embotellada en distintos puntos de comercialización e incluso en sus propias viviendas en el caso que las empresas tengan el servicio de distribución.

Claramente el derecho humano al agua no solo requiere que el agua esté disponible en términos de cantidades, sino que su calidad sea aceptable para el uso personal o doméstico y en este sentido se encuentre libre de sustancias que pongan en peligro la salud. Lo cual requiere que los Estados, garantes de los derechos humanos, establezcan parámetros de calidad mediante la regulación jurídica (Cáceres, 2019). 
A nivel internacional, las "Guías para la calidad del agua potable" de la Organización Mundial de la Salud (OMS) conforman un instrumento que apunta a contribuir a la generación de estándares de calidad del agua. Las Guías explican los requisitos necesarios para garantizar la inocuidad del agua, incluidos los procedimientos mínimos y valores de referencia, por lo que cumplen una función preventiva del riesgo, que apunta a evitar un daño en la salud y parten de considerar que el control de la calidad del agua demanda un conjunto de acciones que incluyen una combinación de medidas como la protección de las fuentes de abastecimiento de agua, de control de las operaciones de tratamiento, y de gestión de la distribución (OMS, 2006). Los parámetros que acuerdan constituyen una referencia para la regulación de la calidad del agua de red o envasada e incluyen aspectos microbiológicos, químicos, y radiológicos.

Una de las enfermedades conocidas en Argentina, hace más de un siglo, es el hidroarsenicismo crónico regional endémico (HACRE), que se manifiesta progresivamente con lesiones en la piel y en distintos órganos y no tiene tratamiento curativo. Se trata de una enfermedad que se conoce desde 1913 y fue detectada en habitantes de Bell Ville, provincia de Córdoba. La prevención incluye, como paso central, reducir la exposición a aguas contaminadas y distribuir "aguas 'saludables', libres de agentes contaminantes para el consumo humano, el abrevamiento y para el riego de cultivos" (Gaiolia, González y Amoedoc, 2009, p. 472).

La OMS ha recomendado niveles máximos admisibles en el agua para consumo humano que han pasado de 0,2 mg/l, en 1958, a 0,05 mg/l en 1963, para reducirse a $0,01 \mathrm{mg} / \mathrm{l}$ en 1993, en la medida que se ha acumulado conocimiento sobre el efecto del arsénico (Cáceres y Minaverry, 2019). La OMS reconoce "las dificultades prácticas para eliminar el arsénico del agua de consumo humano, sobre todo en pequeños sistemas y de alcanzar el límite práctico de cuantificación para el arsénico", por lo que "mantiene el valor de referencia de $10 \mu \mathrm{g} / \mathrm{l}$ como una meta y se designa como provisional" (OMS, 2011, p. 374).

El carácter de la recomendación como provisional se vincula con la incertidumbre sobre los efectos en la salud de la población y a las dificultades de remoción del arsénico en el agua potable y la medición de concentraciones tan bajas (Red de Seguridad Alimentaria del CONICET, 2018).

\section{III.2. La regulación jurídica de la calidad del agua embotellada en la República Argentina}

La calidad del agua envasada y comercializada en la República Argentina se regula mediante una normativa federal, el denominado Código Alimentario Argentino sancionado por la ley 18.284. Esta norma diferencia entre los tipos de aguas que 
se comercializan: agua envasada o de mesa, mineralizada y agua mineral. Aunque se ubican en la misma categoría alimentaria no se trata de los mismos productos. "El agua envasada o de mesa refiere al agua de bebida envasada o agua potabilizada envasada a un agua de origen subterráneo o proveniente de un abastecimiento público, al agua que se comercializa envasada en botellas, contenedores u otros envases adecuados, provistos de la rotulación reglamentaria y que cumpla con las exigencias del presente artículo" (artículo 983, ley 18.284, modificado por Resolución conjunta 34/2019 de la Secretaría de Alimentos y Bioeconomía y Secretaría de Regulación y Gestión Sanitaria).

Esta agua se denomina en el mercado como "agua de bebida embotellada (o envasada)", "agua potable embotellada (o envasada)", "agua tratada embotellada (o envasada)", "agua potable embotellada (o envasada)", "agua tratada embotellada (o envasada)", "agua de mesa embotellada (o envasada)," "soda en botellas".

Mientras que el agua mineral se define como "un agua apta para la bebida, de origen subterráneo, procedente de un yacimiento o estrato acuífero no sujeto a influencia de aguas superficiales y proveniente de una fuente explotada mediante una o varias captaciones en los puntos de surgencias naturales o producidas por perforación". Y que tiene como características su tenor en minerales y sus respectivas proporciones relativas, oligo-elementos y/u otros constituyentes; su pureza microbiológica original; y la constancia de su composición y temperatura en la captación las que deberán permanecer estables en el marco de las fluctuaciones naturales (artículo 985, ley 18284). En este sentido, se denominará con expresiones como "agua mineral natural de manantial de mesa" o "agua mineral natural de manantial" o "agua mineral natural de mesa" o "agua mineral natural" (artículo 988, ley 18284).

Además, reconoce un tipo de "agua mineralizada artificialmente" como aquel "producto elaborado con agua potable adicionada de minerales de uso permitido, gasificada o no, envasada en recipientes bromatológicamente aptos, de cierre hermético e inviolable" (artículo 995, ley 18284, modificado por Resolución conjunta 34/2019 de la Secretaría de Alimentos y Bioeconomía y Secretaría de Regulación y Gestión Sanitaria).

Por lo señalado, el agua embotellada envasada puede tener un origen amplio que en el país incluye la explotación de fuentes de agua como el acuífero Puelche, mediante perforaciones, hasta agua de manantiales de la cordillera de Los Andes. Las características, requisitos de los envases, la calidad, pureza y el rotulado se encuentran establecidos, también, en el Código Alimentario.

Como señalamos, en la República Argentina los parámetros del agua para consumo humano se regulan mediante el Código Alimentario mediante la ley nacional 
18.284 de 1969 que estableció las disposiciones higiénicas, bromatológicas y de identificación del Reglamento Alimentario. El Código incluye regulaciones de los alimentos y establecimientos productores, elaboradores y comercializadores de dichos productos, envases, aparatos y accesorios para alimentos y técnicas analíticas afines. Es decir, se trata de una normativa que promueve la protección de la salud de la población y el acceso a alimentos que tengan garantizado la inocuidad como un valor agregado en calidad.

La adecuación de la República Argentina a la recomendación que realiza la OMS ha transitado y aún transita un proceso complejo, de resistencia por parte de los actores de la industria del agua. En 2007 las autoridades de dos agencias estatales claves, la, por entonces, Secretaría de Políticas, Regulación y Relaciones Sanitarias del Ministerio de Salud de Nación y de la Secretaría de Agricultura, Ganadería, Pesca y Alimentos del Ministerio de Economía y Producción, mediante Resolución conjunta acordaron la adecuación al límite 0,01 mg/l (resoluciones 68/2007 y 196/2007). Hasta entonces el Código Alimentario establecía un máximo de $0,05 \mathrm{mg} / \mathrm{l}$.

En 2012 se autorizó una prórroga de 5 años para su adecuación en el caso que la composición del agua de la zona lo requiriera o existiera imposibilidad de aplicar tecnologías de corrección. Cumplido el plazo se volvió a autorizar la distribución de agua con mayores niveles de arsénico que lo recomendado por la OMS. En paralelo, se han observado dos situaciones, por un lado, la presentación de diversos proyectos de ley o resolución que proponen reconocer el derecho humano al agua, dejar sin efecto las disposiciones que han otorgado prórrogas al cumplimiento de la adecuación, o pedidos de información respecto a la población afectada con HACRE. Entre ellos, los proyectos 1838-D-2018, 0271-D-2017, 1788D-2015, 5088-D-2012. Por otro, en un marco de reclamos de distintos actores de la sociedad civil por la presencia de elevados niveles de arsénico en el agua por red, el Poder Judicial sentó jurisprudencia sobre el derecho al agua, y la máxima instancia, la Corte Suprema de Justicia de la Nación, falló a favor de la adecuación del agua por red a $0,01 \mathrm{mg} / \mathrm{l}$ en 2013 y luego en 2014. Estos fallos tienen su origen en la situación de la provincia de Buenos Aires que adhirió al Código Alimentario en 2013 y aún tiene vigente un marco regulatorio del servicio de agua que habilita la distribución de agua con calidades distintas (decreto 878/2003).

Hacia fines de 2019 se modificaron artículos centrales en materia de los parámetros de agua (982, 983 y 995) y se efectuó, nuevamente, mediante la Resolución conjunta 34/2019 de la Secretaría de Alimentos y Bioeconomía y la Secretaría de Regulación y Gestión Sanitaria. Esta modificación se trató en un ámbito en el que participaron las distintas jurisdicciones del país denominado: Comisión Nacional de Alimentos (CONAL), dependiente del Ministerio de Salud. La CONAL es un 
organismo técnico con participación de las distintas jurisdicciones del país que asesora, apoya y realiza un seguimiento del Sistema Nacional de Control de Alimentos, establecido por el decreto 815 de 1999. Este organismo tiene la función de realizar el seguimiento respecto del cumplimiento del Código Alimentario y para eso establece distintos grupos de trabajo que se conforman sobre problemas específicos, entre ellos se encuentran: sobre contaminantes inorgánicos, sobre bebidas analcohólicas y sobre la actualización del capítulo XX: Metodología analítica oficial. Estos grupos cuentan con especialistas de distintos organismos nacionales y provinciales. El grupo sobre contaminantes inorgánicos participó en la última modificación del Código Alimentario en lo que refiere al arsénico, los artículos agua 982, 983 y 995. En su reunión ordinaria de septiembre de 2018, Acta 124 de la CONAL, según consta en el anexo 12 se determinó la nueva modificación. Previo a esto, el grupo realizó un relevamiento de 110 muestras de agua de bebida envasada y de los resultados obtenidos, en vista de la posibilidad de realizar tratamiento para la reducción de arsénico, concluyó en ratificar el límite máximo de 0,01mg/l establecido en el artículo 983 del CAA (Acta 124, anexo 12 de la CONAL).

La resolución conjunta 34/2019 estableció nuevamente un nivel de arsénico (máx. 0,01 mg/l) para el agua potable de suministro público y agua potable de uso domiciliario, pero abrió la posibilidad que, en algunas zonas del país "cuando la composición normal del agua de la zona y la imposibilidad de aplicar tecnologías de corrección lo hicieran necesario" la autoridad sanitaria competente admita valores mayores con un límite máximo de $0,05 \mathrm{mg} / \mathrm{l}$. Esta adecuación de la redacción la promovió el grupo sobre contaminantes inorgánicos de la CONAL, hasta contar con los resultados del estudio Hidroarsenicismo y Saneamiento Básico en la República Argentina. Este estudio se anunció hace varios años y no se ha publicado un informe final aún, aunque según reportes oficiales existen resultados parciales y se efectúa en el ámbito de la ex Subsecretaría de Recursos Hídricos de la Nación.

Para el caso del agua de bebida envasada o agua potabilizada envasada se admite el valor máximo de $0,01 \mathrm{mg} / \mathrm{l}$ y también habilita la distribución de agua con otra composición que "deberá consignar en el rotulado la localidad de elaboración y no podrá expenderse fuera de ella" (Resolución conjunta 34/2019).

Así estableció que el "agua mineralizada artificialmente" debe cumplir el nivel de arsénico previsto para el tipo de agua de bebida envasada o agua potabilizada envasada (máx. 0,01 mg/l). En este caso la resolución última redujo notoriamente el valor de arsénico exigido anteriormente (máx. 0,2 mg/l), pero no adoptó lo mismo para el agua mineral que sigue en ese valor. Este valor claramente supera los límites admitidos por la OMS. En el mismo espacio de la CONAL, en su reunión ordinaria № 127 de abril de 2019 se hizo referencia al nivel máximo de arsénico en 
agua mineral y sobre la propuesta de reducir el nivel de arsénico en agua mineral de $0,2 \mathrm{mg} / 1$ a $0,05 \mathrm{mg} / 1$.

Esta situación es llamativa dado que el agua embotellada en distintas áreas del país asume la función de un sustituto a la que se distribuye por las redes mediante el servicio público o al agua que se extrae de pozos domésticos dado los niveles de arsénico. En el trabajo de campo realizado en los municipios del interior de la provincia de Buenos Aires San Andrés de Giles, Lobos, Luján, Mercedes y General Rodríguez, durante 2018-2019, se han permitido observar que los hogares adquieren agua embotellada semanalmente como estrategia individual frente al conocimiento de la existencia de niveles de arsénico más elevados en sus regiones. Se observa en las representaciones de parte de la población la consideración que el agua embotellada tiene mejor calidad que el agua de la red, lo cual se nutre de la publicidad que realizan las empresas asociadas a la naturaleza, en la pureza, entre otros aspectos.

El Código Alimentario obliga en el caso de agua de bebida envasada o agua potabilizada envasada que se suministre en recipientes destinados a los consumidores con los materiales aprobados por la misma norma y obliga a que se indique: la denominación mediante las expresiones "agua de bebida embotellada (o envasada)", "agua potable embotellada (o envasada)", "agua tratada embotellada (o envasada)", "agua de mesa embotellada (o envasada)", "soda en botellas"; la marca registrada, la razón social y domicilio de la planta, tratamiento eventual al que pudo haber sido sometida; número de registro del producto y del establecimiento; fecha de duración máxima que se deberá indicar mediante la expresión "consumir preferentemente antes de (...)"; identificación de la partida o día, mes y año de elaboración; la indicación "gasificada" cuando se le tenga incorporado gas carbónico. Se exceptúa de esta indicación a los productos rotulados "soda" o "soda en botellas" y afirma que "los nombres de fantasía o marcas no serán de fuentes o localidades donde se obtenga o hubiera obtenido agua mineral natural" (artículo 983, incisos a, b, c, d, f, g y h). Así también sostiene que "optativamente se incluirán los datos referidos a la composición química o el resultado de análisis efectuado por la autoridad sanitaria competente en el momento de autorizar el producto y/o los resultados del análisis microbiológico o mencionar que la calidad microbiológica cumple con las normas oficiales" (artículo 983, inc. e).

Además, con la intención de no inducir a los consumidores, la norma no autoriza que se agreguen en las etiquetas "cualquier forma de publicidad imágenes de fuentes, cascadas u otra forma de representación que puedan sugerir agua mineral" (artículo 983, inc. I).

Respecto de las aguas mineralizadas artificialmente, aquellas elaboradas con agua a las que se le adicionan minerales, las empresas tienen que cumplir con 
los parámetros microbiológicos y de compuestos químicos y contaminantes establecidos para el agua mineral, a excepción del nivel de arsénico que tiene que cumplir con los requisitos establecidos para el agua de bebida envasada o agua potabilizada envasada. Además, establece que los "nombres de fantasía o marcas no serán de fuentes o localidades donde se obtengan o hubieren obtenido aguas minerales naturales" y se rotulará "agua mineralizada artificialmente con caracteres de buen tamaño realce y visibilidad" (artículo 995, inc. c).

Respecto a las aguas minerales, las empresas están obligadas a informar, además, la "clasificación correspondiente de acuerdo con el grado de mineralización, a la composición y al contenido gaseoso" (artículo 988, inc. e) y les queda prohibido utilizar publicidad que sugiera o atribuya "a un agua mineral natural propiedades de prevención, tratamiento o cura de cualquier tipo de enfermedad en los envases y en los rótulos" (artículo 989, inc. 2).

\section{III.3. Relevamiento exploratorio del mercado de agua embotellada y su impacto en los derechos de los consumidores}

De acuerdo con el Código Alimentario Argentino, las empresas que comercializan agua embotellada requieren brindar un conjunto de datos que hacen a la información sobre el proceso de producción involucrado, ya descripta en la anterior sección.

A fines de 2019 se realizó un relevamiento de una muestra de 10 empresas que se desempeñan en el sector de agua embotellada con distintos tipos de agua (mineral, mineralizada, y de mesa solo). Este relevamiento incluyó a las marcas: Eco de los Andes; Glaciar; Nestlé Pureza Vital; Villavicencio; Villa del Sur; Sierra de los Padres; Nihuil; Kin; Ivess y Agua Polar. Estas marcas comercializan agua mineral de manantial, aguas de mesa y aguas mineralizadas dado que utilizan fuentes que incluyen desde agua de manantiales que se originan en la infiltración de la nieve en las sierras de Uspallata y el Cordón de los Paramillos, en el caso del agua Villavicencio, o de manantiales atermales de Mendoza, en el caso de agua Eco de los Andes, hasta agua extraída del Acuífero Puelche en el caso del agua de mesa Nihuil que afronta un proceso de ósmosis inversa para adquirir la calidad que se norma.

En el Cuadro No 1 se presenta la información relevada de las etiquetas de las marcas: tipo de agua, fuente, y componentes minerales que contiene. Solo en uno de los casos, la marca Agua Polar, ubicada en la provincia de Buenos Aires en el distrito de Moreno, informa a los consumidores el nivel de arsénico que tiene el agua menor a $0,01 \mathrm{mg} / \mathrm{l}$. 


\begin{tabular}{|c|c|c|c|}
\hline 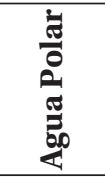 & 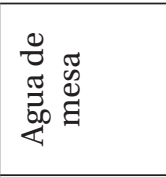 & 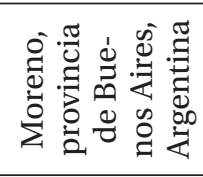 & 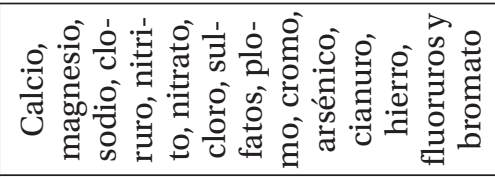 \\
\hline 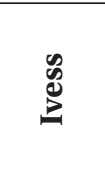 & 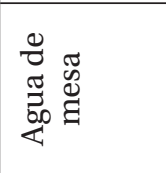 & 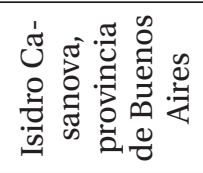 & 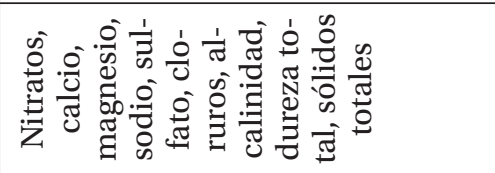 \\
\hline$\Xi$ & 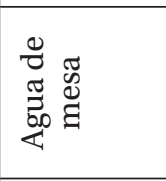 & 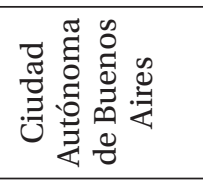 & 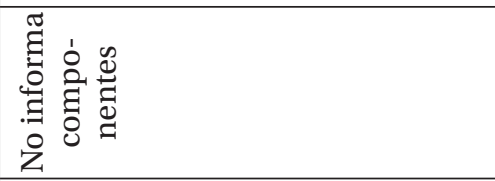 \\
\hline 竞 & 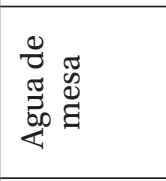 & 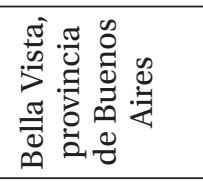 & 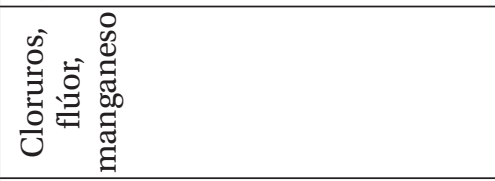 \\
\hline 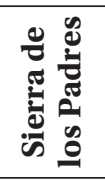 & 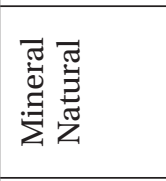 & 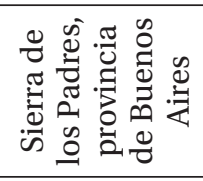 & 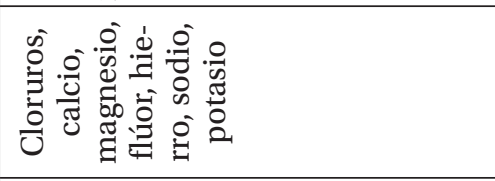 \\
\hline 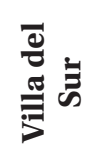 & 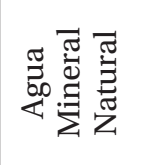 & 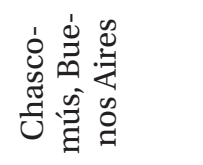 & 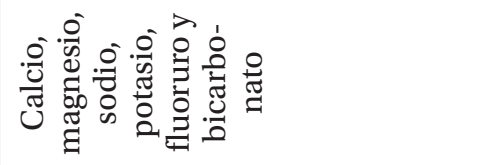 \\
\hline 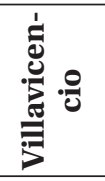 & 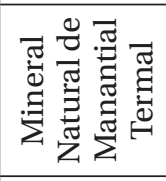 & 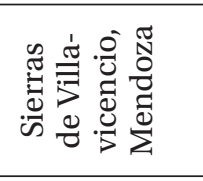 & 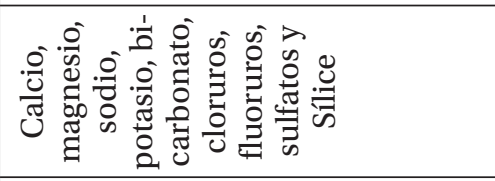 \\
\hline 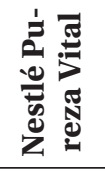 & 咅 & 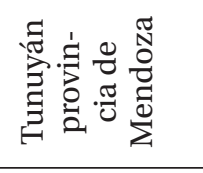 & 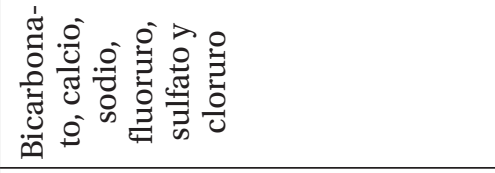 \\
\hline 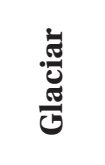 & 苙宽 & 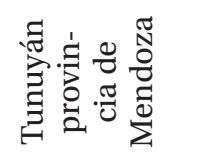 & 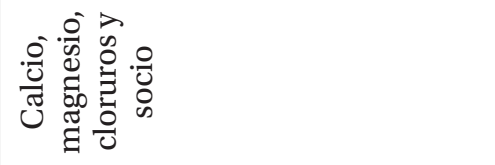 \\
\hline 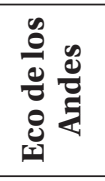 & 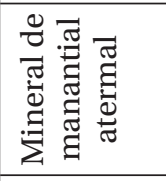 & 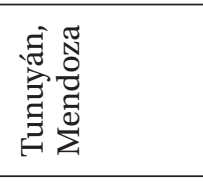 & 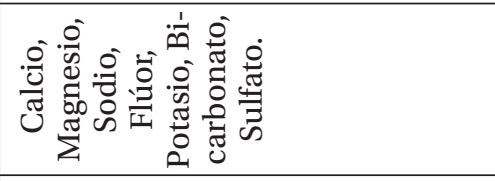 \\
\hline 胥 & 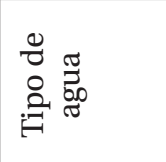 & 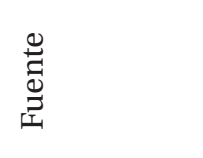 & 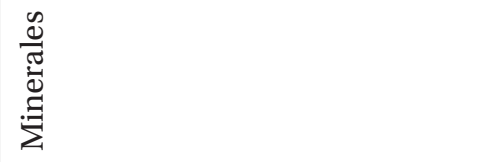 \\
\hline
\end{tabular}


Desde el ámbito del derecho del consumidor, el artículo 42 de la Constitución Nacional, el artículo 38 de la Constitución de la provincia de Buenos Aires, la ley nacional 24.240 (de defensa del consumidor) de 1993, y la ley 26.994 (en adelante Código Civil y Comercial de la Nación) de 2015, se incorporaron diversos lineamientos vinculados con el derecho que tienen los consumidores a acceder a una información adecuada y veraz. En el artículo 4 de la ley 24.240 se establece que el proveedor está obligado a suministrar al consumidor en forma cierta, clara y detallada todo lo relacionado con las características esenciales de los bienes y servicios que provee, y las condiciones de su comercialización. Algo similar se establece en el artículo 1100 del Código Civil y Comercial de la Nación.

El decreto de necesidad y urgencia 274/2019 regula el régimen en materia de lealtad comercial, que derogó al anterior del año 1983. En el mismo se destaca uno de los supuestos de competencia desleal (que podría aplicársele a las empresas o municipios que brinden el servicio público del agua), que es el acto de engaño sobre la naturaleza, modo de fabricación, características principales y condiciones de los bienes y servicios. En este caso, los consumidores de agua embotellada podrían ser considerados, en algunas situaciones, como engañados y escasamente informados sobre las condiciones del mismo.

\section{El particular caso del noreste de la provincia de Buenos Aires y la percepción de la población}

La provincia de Buenos Aires posee una extensión que alcanza los $304.907 \mathrm{~km}^{2}$, que es equivalente a $11,1 \%$ del territorio argentino, se ubica en el centro-este del país, y se encuentra integrada por 135 partidos. Estos últimos son jurisdicciones político-administrativas de segundo orden y coinciden con las áreas de gobierno local, que son los municipios. En términos demográficos, en 2010 la población total ascendía a 15.762 .098 , lo cual representa el 38,97 \% del país. Por un lado, se encuentran los partidos del Gran Buenos Aires (GBA) o conurbano bonaerense, que están integrados por 24 municipios que rodean a la Ciudad Autónoma d Buenos Aires (CABA). Por el otro lado, se encuentra el interior provincial, conformado por 111 Partidos, donde se localiza el resto de la población (Minaverry y Cáceres, 2016) (Cáceres y Minaverry, 2019). En la provincia de Buenos Aires (contando el área metropolitana y el interior), el alcance del servicio de agua de red es del $75,1 \%$ (INDEC, 2010). Estos últimos tampoco se encuentran exentos de sufrir inconvenientes. Así, en ambos casos, millones de personas deben enfrentar diariamente la disyuntiva entre abastecerse con agua de mala calidad o destinar una gran cantidad de dinero para comprarla embotellada. (Cáceres, Minaverry, 2019).

En este contexto de análisis se realizaron encuestas a 175 personas que habitan o trabajan en el casco urbano de los siguientes partidos del noreste de la provincia 
de Buenos Aires: San Andrés de Giles, Lobos, Luján, Mercedes y General Rodríguez, desde marzo de 2018 hasta marzo de 2020. Las encuestas fueron realizadas personalmente o en línea, al azar y a todos los encuestados se les solicitó contestar un cuestionario con 13 preguntas vinculadas con diversos aspectos del agua para consumo humano con un formato de múltiple opción y la posibilidad de realizar aclaraciones. Para este trabajo se seleccionaron tres preguntas en particular que se relacionan directamente con la problemática aquí planteada y se presentan en los cuadros a continuación. El Cuadro № 2 hace referencia a los resultados obtenidos respecto de la siguiente pregunta: ¿Compra agua embotellada?

Cuadro No 2: Población encuestada que adquiere agua embotellada

\begin{tabular}{|c|c|c|c|c|c|c|}
\hline \multicolumn{2}{|c|}{} & $\begin{array}{c}\text { General } \\
\text { Rodríguez }\end{array}$ & $\begin{array}{c}\text { San Andrés } \\
\text { de Giles }\end{array}$ & Lobos & Luján & Mercedes \\
\hline Sí & $\mathbf{9 5}$ & 14 & 16 & 24 & 14 & 27 \\
\hline No & $\mathbf{7 9}$ & 20 & 19 & 11 & 21 & 8 \\
\hline No contesta & $\mathbf{1}$ & 1 & & & & \\
\hline TOTAL & $\mathbf{1 7 5}$ & 35 & 35 & 35 & 35 & 35 \\
\hline
\end{tabular}

Fuente: elaboración propia.

Se destaca que la mayoría de los encuestados informó que consumía agua embotellada, aproximadamente el $54 \%$ contestó que preferían adquirir dicho producto en lugar del agua de red. Los resultados más altos se detectaron en los partidos de Lobos y de Mercedes que justamente poseen altos niveles de arsénico en su agua de red.

El Cuadro No 3 hace referencia a los resultados obtenidos respecto de la siguiente pregunta: ¿Ha efectuado un análisis bacteriológico o químico del agua y cuándo?

Cuadro No 3: Población encuestada que realiza análisis bacteriológico o químico del agua

\begin{tabular}{|c|c|c|c|c|c|c|}
\hline \multicolumn{2}{|c|}{} & $\begin{array}{c}\text { General } \\
\text { Rodríguez }\end{array}$ & $\begin{array}{c}\text { San Andrés } \\
\text { de Giles }\end{array}$ & Lobos & Luján & Mercedes \\
\hline Sí & $\mathbf{2}$ & & & & 2 & \\
\hline Sí, hace 6 meses & $\mathbf{3}$ & 1 & & 1 & & 1 \\
\hline Sí, hace 1 año & $\mathbf{8}$ & 2 & 1 & 3 & 1 & 1 \\
\hline Sí, hace 2 años & $\mathbf{5}$ & 1 & 2 & 1 & 1 & \\
\hline Sí, hace 3 años & $\mathbf{1}$ & & & & 1 & \\
\hline Sí, hace 5 años & $\mathbf{1}$ & & & & 1 & \\
\hline Sí, hace 10 años & $\mathbf{1}$ & & & & 1 & \\
\hline
\end{tabular}




\begin{tabular}{|c|c|c|c|c|c|c|}
\hline \multicolumn{2}{|c|}{} & $\begin{array}{c}\text { General } \\
\text { Rodríguez }\end{array}$ & $\begin{array}{c}\text { San Andrés } \\
\text { de Giles }\end{array}$ & Lobos & Luján & Mercedes \\
\hline Otro & $\mathbf{9}$ & 3 & 1 & 2 & & 3 \\
\hline No & $\mathbf{1 4 5}$ & 28 & 31 & 28 & 28 & 30 \\
\hline TOTAL & $\mathbf{1 7 5}$ & 35 & 35 & 35 & 35 & 35 \\
\hline
\end{tabular}

Fuente: elaboración propia.

Según surge de los resultados presentados en el Cuadro № 3, la gran mayoría de los encuestados no ha realizado análisis bacteriológicos ni químicos del agua de red (el 82\%), pero, sin embargo, en el Cuadro No 2 pudimos ver que sin tener esta información de todas maneras en su mayoría consumían agua embotellada. Ciertamente queda una parte de la muestra que no ha realizado análisis y que tampoco consumía agua embotellada demostrando un alto nivel de indiferencia respecto de la presente problemática.

El Cuadro No 4 hace referencia a los resultados obtenidos respecto de la siguiente pregunta: ¿Escuchó hablar sobre el arsénico?

Cuadro No 4: Población encuestada que responde haber escuchado o no, hablar del arsénico en el agua

\begin{tabular}{|c|c|c|c|c|c|c|}
\hline \multicolumn{2}{|c|}{} & $\begin{array}{c}\text { General } \\
\text { Rodríguez }\end{array}$ & $\begin{array}{c}\text { San Andrés } \\
\text { de Giles }\end{array}$ & Lobos & Luján & Mercedes \\
\hline Sí & $\mathbf{1 1 1}$ & 22 & 23 & 31 & 15 & 20 \\
\hline No & $\mathbf{6 2}$ & 13 & 11 & 4 & 20 & 14 \\
\hline NS/NC & $\mathbf{2}$ & & 1 & & & 1 \\
\hline TOTAL & $\mathbf{1 7 5}$ & 35 & 35 & 35 & 35 & 35 \\
\hline
\end{tabular}

Fuente: elaboración propia.

En el Cuadro No 4 se puede visualizar que la mayoría de los encuestados manifestó que tenía conocimiento sobre la existencia de la problemática de los altos niveles de contaminación por arsénico en el agua de su región.

Se destacan a continuación algunos de las afirmaciones textuales que realizó la población encuestada, como es en el caso del partido de San Andrés de Giles, donde afirmaron que compraban agua embotellada porque:

. "La que provee el servicio tiene mucho cloro".

. "El agua de red es no apta para consumo".

. "Por el sarro". 
- "Porque tengo nenes chiquitos"

- "Por falta de confianza en el agua de red".

. "Porque tiene gusto a cloro".

. "Porque tiene mejor gusto".

En la misma pregunta, dos encuestados afirmaron que no compraban agua embotellada porque en sus domicilios poseían agua potable y que podía tomarse sin ningún problema.

En el partido de Lobos también varios encuestados contestaron que no querían consumir el agua de red y que compraban agua embotellada por las siguientes razones:

. "Porque tiene cloro".

. "Porque tengo niños en casa".

. "Porque el agua de red tiene arsénico" (fue contestado por 3 personas).

En el partido de Mercedes contestaron que compran agua embotellada porque:

• “Tengo nenes chicos, por seguridad".

. "Para los clientes".

. "Vivo en un edificio y no hacen mantenimiento".

. "Por seguridad, por mi familia".

. "Porque no confío".

- "Porque se dice que el agua de red tiene arsénico a un nivel más alto del que debería".

. "Porque es muy salitrosa".

. "Porque tiene feo gusto".

En el partido de General Rodríguez los encuestados justificaron la compra de agua embotellada por las siguientes razones:

• "Porque muchas veces el agua tiene sabor a cloro".

• "Por seguridad". 
. "Porque no me gusta el sabor del agua".

- "Para tomar agua en condiciones de ser consumida".

. "Porque el agua corriente tiene sabor a lavandina".

En cambio, en el partido de Luján, una gran cantidad de los encuestados contestaron que no compraban agua embotellada y lo justificaron de la siguiente manera:

. "No lo creo necesario" (7 casos).

. "No necesito, uso perforación de agua".

- "En casa tomo el agua de la canilla y en el trabajo del dispenser".

• "Confío en el agua de red".

. "Creo que es potable el agua que consumo. Compro agua con gas (soda)".

. "Porque no puedo costearla y porque el agua corriente es potable".

• "Uso el agua de la canilla".

Es relevante destacar que el derecho a la información y su debido acceso a toda la población posee un efecto directo en los resultados obtenidos en las encuestas, en particular en lo vinculado con las justificaciones sobre por qué razón compraban agua embotellada en lugar de consumir la de red. En la mayoría de los casos las respuestas obtenidas por los encuestados no se vinculaban ni con el conocimiento sobre el cumplimiento de los requisitos legales que determina si el agua es potable, ni sobre la existencia de contaminaciones naturales como la de arsénico en determinadas zonas donde se encuentran tramitando causas judiciales y/o donde existen diversos estudios científicos que afirman sobre su existencia. El derecho a la educación ambiental también cumple un papel fundamental en estas problemáticas porque podría brindar herramientas a la población para exigir a los organismos de control públicos correspondientes el control de la calidad del agua embotellada para que sea considerada potable según las recomendaciones internacionales vigentes.

A su vez todo lo planteado en este trabajo se complejizó aún más teniendo en cuenta lo que señala un informe reciente en relación con la situación de aislamiento provocada por el COVID-19 elaborado por el Consejo Nacional de Investigaciones Científicas y Técnicas, en donde se pudo constatar que actualmente existen mayores dificultades para los grupos sociales con mayor vulnerabilidad 
o que residen en áreas geográficas menos integradas, que se traducen en problemas relacionados con el acceso al agua potable o que directamente se produce la escasez de la misma para mantener higienizadas a las personas y a las viviendas (Kessler et al, 2020).

\section{Conclusiones}

En las últimas tres décadas se incrementó la mercantilización del agua y, en el ámbito del consumo humano, el agua embotellada se consolidó en un mercado diversificado. En este, el Estado regula la composición que debe contener el agua y las características que deben presentar los envases y los rotulados de los productos que se exhiben. El agua embotellada cuenta con una amplia población que la consume y en las áreas donde la población y distintos actores sociales y económicos acceden a información respecto de la situación del arsénico en el agua que se distribuye en el servicio público o de la que se autoabastecen mediante perforaciones domésticas, el consumo de agua embotellada adquiere relevancia. "El arsénico es un problema en materia de calidad que demanda atención, se trata de un elemento tóxico que se encuentra presente de forma natural, dado la disolución de minerales arsenicosos relacionados con las erupciones volcánicas y a la actividad hidrotermal, especialmente en la Cordillera de los Andes, en los últimos 5 millones de años y que se mantiene actualmente, de forma más atenuada" (Auge, 2009, p. 2).

Frente al debate que se observa respecto a los límites legales de arsénico en el agua para consumo humano y las prórrogas en la adecuación a lo que recomienda la OMS, la Corte Suprema intervino, primero en 2013, en una causa denominada "Conde, Alberto José Luis y otro contra Aguas Bonaerenses S.A. sobre amparo" que exigía a ABSA que distribuyera agua con niveles de arsénico menores a $0.01 \mathrm{mg} / \mathrm{l}$. En esa oportunidad señaló:

(...) que los niveles de arsénico en las aguas de consumo humano no deberían exceder bajo ningún concepto el límite establecido en el Código Alimentario Argentino (2007) y las normativas internacionales (WHO) que se ha fijado en $0.01 \mathrm{mg} / \mathrm{L}$. Para el caso de embarazadas, lactantes y niños de hasta 3-4 años la provisión de agua segura, con niveles de arsénico de hasta $0.01 \mathrm{mg} / \mathrm{L}$ debería ser obligatoria, ya que se ha demostrado que el arsénico puede producir daños fetales que se expresan en la niñez (CSJN, "Conde, Alberto José Luis y otro contra Aguas Bonaerenses S.A. sobre amparo", 2013, p. 2).

Actualmente las empresas que comercializan agua embotellada no están obligadas a informar el componente de arsénico que tiene, en tanto se encuentra regulada por normativa de larga data y que no sido adecuadamente actualizada 
conforme a la realidad ambiental actual. Esto puede interferir con el derecho a la información de los consumidores y a sufrir las consecuencias de la publicidad engañosa los cuales se encuentran garantizados por el artículo 42 de la Constitución Nacional.

Por su parte, la población del noreste de la provincia de Buenos Aires que fue encuestada posee ciertos conocimientos relacionados con el concepto de que el agua embotellada presenta una calidad superior a la de red, cuestión que muchas veces no coincide con la realidad y que condiciona su consumo respecto de dicho producto.

En relación con la regulación jurídica de la problemática planteada en este trabajo se detectaron lineamientos que, en algunos casos, son contradictorios e insuficientes, exhibiendo una situación de debilidad del derecho que no logra proteger a la población exigiendo productos seguros vinculados con la provisión de agua potable. Sumado a todo lo anterior, para la resolución de estas cuestiones el derecho debería contar con la colaboración de un equipo de profesionales y de expertos de carácter interdisciplinario. Todo lo anterior se justifica en la extrema complejidad que presentan las mismas y en que también podrían aportar sus conocimientos para la resolución de las causas y/o para el dictado de políticas públicas.

\section{Bibliografía}

Auge, M. (2009) Arsénico en el agua subterránea. La Plata. Recuperado de https:// manuelmorrone.files.wordpress.com/2015/04/arsc3a9nico-en-el-agua_.pdf

Bruzone, A. (2000). Informe sobre bebidas. Revista Alimentos Argentinos, 12. Dirección de Industria Alimentaria - S.A.G.P. y A. Recuperado de http://www.alimentosargentinos.gob.ar/contenido/revista/ediciones/12/Bebidas.PDF

Cáceres, V. y Minaverry, C. (2019). El arsénico en el servicio público de agua en la provincia de Buenos Aires: vulneración de derechos. En C. Minaverry y V. Cáceres (comp.), Dinámicas sociales, ambientales y turísticas en torno al agua (pp. 59-77). Los Polvorines: Editorial Universidad Nacional de General Sarmiento.

Castro, J. E. (2009). Apuntes sobre el Proceso de Mercantilización del Agua: Un Examen de la Privatización en Perspectiva Histórica. En A. Santiago Espinoza (ed.), Justicia Ambiental y Sustentabilidad Hídrica (pp. 11-29). Bolivia: CESU - UMSS. Recuperado de https://www.staff.ncl.ac.uk/j.e.castro/CGIAB.pdf

Comisión de Ciencias Sociales de la Unidad Coronavirus COVID-19, Ministerio de Ciencia, Tecnología e Innovación de la Nación (2020). Relevamiento 
del impacto social de las medidas del Aislamiento dispuestas por el PEN. Buenos Aires: Comisión de Ciencias Sociales de la Unidad Coronavirus COVID-19 (MINCYT-CONICET-AGENCIA).

Congreso Argentino de Aguas Subterráneas “Aguas Subterráneas y Desarrollo Humano" (2002) Arsénico en las aguas subterráneas: su impacto en la salud. Bocanegra. E., Martínez D., Massone H. Mar del Plata: Universidad Nacional de Mar del Plata. ISBN 978-987-544-063-0.

Congreso Latinoamericano de estudios urbanos (2019). El desafío de la calidad del agua en el interior bonaerense: el caso del arsénico en 9 de Julio. Los Polvorines: Editorial Universidad Nacional de General Sarmiento.

Gaiolia, M.; González, D. y Amoedoc, D. (2009). Hidroarsenisismo crónico regional endémico: un desafío diagnóstico y de prevención. Pediatría práctica, 107 (5) (pp. 459-473). Recuperado de https://www.sap.org.ar/docs/publicaciones/archivosarg/2009/v107n5a18.pdf [Fecha de consulta: 14/01/2020].

García, S. (2011). Hidroarsenicismo Crónico Regional Endémico HACRE: Módulo de Capacitación. Buenos Aires: Ministerio de Salud de la Nación. Programa Nacional de Prevención y Control de las Intoxicaciones.

Garzonio, O. y Núñez, J. (2012). La vida sin construcción. Sector Agua y Saneamiento. Buenos Aires: Cámara Argentina de la Construcción, Área de Pensamiento Estratégico.

Godelier, M. (1974). Antropología y economía. Barcelona: Editorial Anagrama.

Instituto Nacional de Tecnología Industrial (INTI) (2011). Programa Pruebas de desempeño de productos. Aguas de mesa. Buenos Aires: INTI. Recuperado de www. inti.gob.ar/productos [Fecha de consulta:03/12/2019].

Kessler, G. et al (2020). Relevamiento del impacto social de las medidas del Aislamiento dispuestas por el PEN. Comisión de Ciencias Sociales de la Unidad Coronavirus COVID-19, CONICET. Recuperado de https://www.conicet.gov.ar/wpcontent/uploads/Informe_Final_Covid-Cs.Sociales-1.pdf

Ministerio del Interior, Obras Públicas y Vivienda (2017). Plan Nacional de Agua Potable y Saneamiento. Cobertura Universal y Sostenibilidad de los servicios. Lineamientos y principales acciones, 2da ed. Buenos Aires.

Minaverry, C. y Cáceres, V. (2016). La problemática del arsénico en el servicio de agua en la provincia de buenos aires, argentina. Análisis de casos jurisprudenciales. Rev. Int. Contam. Ambie, 32 (1) (pp. 69-76). Recuperado de https://www. 
researchgate.net/publication/305356266_La_problematica_del_arsenico_en_el_ servicio_de_agua_en_la_provincia_de_Buenos_Aires_Argentina_Analisis_de_casos_jurisprudenciales [Fecha de consulta: 15/01/2020].

OMS (2006). Guías para la calidad del agua potable, tercera edición: Volumen 1 - Recomendaciones. Ginebra, Suiza: Ediciones de la OMS.

ONU (2010). El derecho al agua. Folletos informativos sobre los derechos humanos (35). Recuperado de https://www.ohchr.org/Documents/Publications/FactSheet35sp.pdf [Fecha de consulta: 14/04/2020].

Red de Seguridad Alimentaria Consejo Nacional de Investigaciones Científicas y Técnicas (2018). Informe Final. Arsénico en el agua. Recuperado de https://rsa. conicet.gov.ar/wp-content/uploads/2018/08/Informe-Arsenico-en-agua-RSA. pdf [Fecha de consulta: 10/04/2020].

Titto, E. (2011). Prólogo. En Programa Nacional de Prevención y Control de las intoxicaciones, Hidroarsenicismo Crónico Regional Endémico HACRE: Módulo de Capacitación. 1ra. ed. Buenos Aires: Ministerio de Salud de la Nación.

Villaamil Lepori, E. y Federación Bioquímica de la Provincia de Buenos Aires (2015). Hidroarsenicismo crónico regional endémico en Argentina. Acta Bioquímica Clínica Latinoamericana, vol. 49 (1) (pp. 83-104). Recuperado de https:// www.redalyc.org/pdf/535/53541285009.pdf [Fecha de consulta: 14/01/2020].

\section{Jurisprudencia}

Corte Suprema de Justicia de la Nación, 12/11/2013, "Conde, Alberto José Luis y otro contra Aguas Bonaerenses S.A. sobre amparo". Recuperado dehttp://www. patagonia3mil.com.ar/wp-content/uploads/documentos2/suprema.pdf [Fecha de consulta 16/01/2020].

Fecha de recepción: 30-03-2020

Fecha de aceptación: 08-09-2020 
